\title{
Environmental Toxicants and Testicular Apoptosis
}

\author{
Premendu P. Mathur ${ }^{2}$, Laura Huang ${ }^{1}$, Anthony Kashou ${ }^{1}$, Selvaraju Vaithinathan ${ }^{2}$ and \\ Ashok Agarwal ${ }^{*}, 1$ \\ ${ }^{1}$ Center for Reproductive Medicine, Cleveland Clinic, 9500 Euclid Avenue, Cleveland, OH 44195, USA \\ ${ }^{2}$ Department of Biochemistry and Molecular Biology, School of Life Sciences, Pondicherry University, Puducherry 605 \\ 014, India
}

\begin{abstract}
When apoptosis is improperly activated or regulated in the testis, infertility or even cancer can result. Studies have implicated elevated rates of apoptosis in infertile male patients. Pinpointing how environmental toxicity affects apoptosis is important for the advancement of preventative medicine and behavior, especially as potentially harmful compounds continue to proliferate in households and workplaces. Moreover, familiarity with testicular processes, particularly the induction of apoptosis, is essential for promoting male fertility. This review examines environmental toxicants that have been implicated in testicular apoptosis. We elucidate the mechanistic pathways through which specific xenobiotic compounds trigger cell death in the testis. This review highlights the role of oxidative stress in mediating these apoptotic actions.
\end{abstract}

Keywords: Oxidative stress, environmental toxicants, apoptosis, spermatogenesis, Leydig cell, Sertoli cell.

\section{INTRODUCTION}

Apoptosis can be a two-faced companion reinforcing tissue homeostasis and physiological processes as a friend, instigating organ dysfunction and disease as a foe [1]. When apoptosis is improperly activated or regulated in the testis, infertility or even cancer can result. Studies have implicated elevated rates of apoptosis in infertile male patients [2]. Pinpointing how environmental toxicity affects apoptosis is important for the advancement of preventative medicine and behavior, especially as potentially harmful compounds continue to proliferate in households and workplaces. Moreover, familiarity with testicular processes, particularly the induction of apoptosis, is essential for promoting male fertility [3]. In male patients with idiopathic infertility, ROS-induced sperm damage is associated with increased apoptosis [4].

This review examines environmental toxicants that have been implicated in testicular apoptosis. We elucidate the mechanistic pathways through which specific xenobiotic compounds trigger cell death in the testis. This review highlights the role of oxidative stress in mediating these apoptotic actions.

\section{PHYSIOLOGY AND PATHOLOGY OF TESTICULAR APOPTOSIS}

Apoptosis occurs under the direction of an active, intracellular death program that can be stimulated or inhibited by environmental agents [5]. Under developmental regulation, apoptosis proceeds in response to: a) deprivation of survival factors, such as testosterone, b) activation by ligated death

*Address correspondence to this author at the Center for Reproductive Medicine, Cleveland Clinic, Desk A19.1, 9500 Euclid Avenue, Cleveland, Ohio 44195, USA; Tel: (216) 444-9485; Fax: (216) 445-6049; E-mail: agarwaa@ccf.org factors, or c) exposure to environmental stimuli, such as radiation, chemotherapeutic drugs, and ROS [6]. By activating caspases, ROS may initiate the propagation of a series of reactions that ultimately trigger apoptosis. Additionally, apoptosis may be induced by cell injury or stress. The principal function of testicular apoptosis is to help maintain tissue homeostasis during spermatogenesis [2].

The reproductive system involves dramatic cycles of tissue growth and degeneration, and spermatogenesis is no exception. Spermatogenesis is the process involving mitosis, meiosis, and cellular differentiation that transforms spermatogonia into mature spermatozoa [7]. During this process, the seminiferous epithelium proliferates rapidly in the testis.

The seminiferous epithelium consists of germ cells and Sertoli cells. Germ cells carry the genetic material and mature into the sperm cells that ultimately fertilize the egg. Helping to regulate the development of nascent sperm cells, Sertoli cells are the somatic cells that provide physical reinforcement to germ cells and mediate the movement of growth factors, hormones and signals into the seminiferous tubules where spermatogenesis commences. Additionally, Sertoli cells contribute to the consumption of excess byproducts after sperm cells have fully developed $[2,6,8]$. Any factor that impairs the viability and function of either germ cells or Sertoli cells may directly affect spermatogenesis.

Testicular apoptosis serves to deplete excess germ cells and remove abnormal spermatozoa during normal spermatogenesis. Indeed, apoptosis eliminates $75 \%$ of germ cells before they become fully mature $[2,3]$. In this way, testicular apoptosis monitors germ cell population according to the support capacity of Sertoli cells [3].

While apoptosis is essential for maintaining testicular homeostasis during spermatogenesis, inappropriately occurring apoptosis has been linked to suboptimal male repro- 
ductive function [2]. Excessive apoptosis results from impaired regulation or improper activation, and can affect spermatogenesis and even lead to infertility $[9,10]$.

\section{PLAYERS AND PATHWAYS INVOLVED IN TESTI- CULAR APOPTOSIS}

Executing apoptosis requires constitutively expressed proteins. Researchers have uncovered the genes for proapoptosis proteins, such as caspases and Apaf-1, and antiapoptosis proteins, such as Bcl-2 [11-13]. These proteins, along with $\mathrm{p} 53, \mathrm{NF}-\kappa \mathrm{B}$, and death receptors, play key roles in human apoptosis. Studying the nature of their responses to xenobiotic toxins may elucidate the mechanisms that oversee environmentally induced apoptosis.

\section{Caspases}

The caspase family consists of different cysteine proteases that modulate apoptosis by cleaving specific intracellular proteins, which can then activate other destructive cell processes [5, 14]. Jacobson et al. have demonstrated that caspase inhibitors block apoptosis in animal cells [5]. Caspases are synthesized as zymogens, and undergo proteolytic activation at specific cleavage sites. Caspases may cleave other capsases [15].

Caspases act in a cascade, in which upstream initiator caspases amplify and integrate pro-apoptotic signals that then activate downstream effector caspases. Caspases-1, -2 , $-4,-5,-8,-9,-10,-11$, and -12 comprise the upstream initiatior caspases. They flock in inactive procaspase form to ligated death receptors, where they then undergo activation. The initiator caspases possess a long N-terminal prodomain, either a caspase recruitment domain (CARD) or a death effector domain (DED), which serves as scaffolding for the aggregation of caspase activating proteins. These protein complexes form as specialized responses to pro-apoptotic signals, and nudge their respective caspase cascades into motion [14]. For example, caspase-9 is activated in the mitochondrial pathway by the apoptosome, which engages with apoptotic protease-activating factor-1 (APAF-1) and cytochrome c. In the death signaling pathway, caspase-8 is triggered by the death inducing signaling complex (DISC), which forms at the Fas receptor. Proteloytic activation of caspases- 8 and -10 ultimately triggers the caspase cascade [16].

The effector caspases consist of capsases- $3,-6,-7$, and -14. Activated initiator caspases send signals to the effector caspases, which then cleave their respective substrates [5, 14]. The target proteins include cytoplasmic structural proteins, such as actin, as well as nuclear proteins, such as PARP and lamins [17-19]. In addition to inducing protein degradation, activated caspase-3 can degrade DNA via proteolytic activation of DNases [20,21]. These varieties of degradation trigger the execution of apoptosis.

\section{Bcl-2 Family Proteins}

Bcl2 and its homologues regulate caspase activation. Among the more than 20 members of the mammalian $\mathrm{Bcl} 2$ family, five proteins are anti-apoptotic $(\mathrm{Bcl}-2, \mathrm{Bcl}-\mathrm{xL}, \mathrm{Bcl}-$ w, A1 and Mcl1) and two subgroups are pro-apoptotic (the $\mathrm{BH} 3$-only proteins and the effector proteins).

The antiapoptotic Bcl2-like proteins are embedded within the mitochondrial outer membrane, and regulate membrane integrity by directing blocking their proapoptotic cousins. Researchers have speculated that the Bcl2-like proteins could also regulate several initiator caspases that are upstream of or removed from mitochondrial disruption, although these caspases would be redundant triggers [22,23].

The pro-apoptotic clan of the Bcl2 family is divided into the BH3-only proteins and the effector proteins (also called the Bax family). The $\mathrm{BH} 1, \mathrm{BH} 2, \mathrm{BH} 3$ and $\mathrm{BH} 4$ motifs from the $\mathrm{Bcl}-2$ like proteins remain highly conserved in the effector proteins, whereas the BH3-only proteins contain only their namesake region. The BH3-only proteins (Bid, Bim, Bik, Bad, Bmf, Hrk, Noxa, Puma) promote apoptosis by inactivating their anti-apoptosis cousins, the Bcl2-like proteins, or by activating effector proteins, Bax and Bak. The balance between anti-apoptosis and $\mathrm{BH} 3$-only proteins determine tissue homeostasis; inactivation of $\mathrm{Bcl} 2$ boosts apoptosis. In addition to directly neutralizing anti-apoptotic proteins, the $\mathrm{BH} 3$-only family contributes to apoptosis by detecting intracellular damage and physiological death cues $[22,23]$.

The Bax family is involved further downstream in mitochondrial disruption. Involved in mediating mitochondrial membrane channels, Bax and Bak contribute to the release of apoptogenic proteins, such as cytochrome $\mathrm{c}$. The mechanism of Bax and Bak activation remains unknown [23].

Non-Bcl-2 family proteins, such as $\mathrm{p} 53$, have also been implicated in the regulation of mitochondrial outer membrane permeability. Cytosolic p53 not only localizes to the mitochondria following stress induction, but also antagonizes Bcl2-like protein and directly activates effector proteins. By stimulating Bax expression, p53 skews the Bax to $\mathrm{Bcl}-2$ ratio and promotes apoptosis [24].

\section{p53}

p53 is the main human tumor suppressor protein, and mediates various cell cycle checkpoints to prevent replication of damaged DNA. To do so, p53 acts via gene regulation to induce cell cycle arrest or apoptosis [25]. p53induced apoptosis occurs physiologically to remove excess or non-intact cells. p53-mediated apoptosis can occur by way of trans-activation, upregulating Bax activity or downregulating Bcl2 activity. When faced with DNA damage, p53 becomes active and can also activate transcription of $\mathrm{p} 21$. p21 gene overexpression stimulates the proapoptotic Bax gene, which warps the Bcl-2:Bax ratio. The transcription factor can also target the BH3-only class of proteins, such as Puma, Noxa and Bid, which act upstream of Bax [24].

The understanding of p53-induced apoptosis has long focused on p53's transcriptional activation of proapoptotic genes, such as BAX, PUMA, FAS/APO-1, NOXA, PIGs, and p53AIP1 [26]. However, p53 possesses a duality that alternates between trans-activation and trans-repression. Although its role as a gene repressor has been less re- 
searched and less understood, a burgeoning wave of studies suggests that p53 can also trigger apoptosis by repressing transcription of antiapoptotic genes. Indeed, researchers showed that $\mathrm{p} 53$ acted as a transcriptional repressor of antiapoptotic genes PLK, PTTG1 and CHEK1, and that inhibiting repression of these specific genes significantly reduced the apoptotic response. Immunoprecipitation and reporter assays showed that p53 targets antiapoptotic signals both directly and indirectly. Speculated mechanisms of indirect gene repression by p53 include interfering with E2Fmediated transcription and recruiting a repressor complex via p21 [27].

If the Bax level is constitutively high, p53 may mediate apoptosis through a transcriptionally independent pathway. Additionally, p53 can induce apoptosis independent of transactivation. Cytoplasmic or mitochondrial p53 can assume the role of $\mathrm{HBH} 3$-only proteins and dimerize with Bcl2 family proteins at the outer mitochondrial membrane. By antagonizing Bcl2 proteins, p53 can free Bax and Bak for apoptotic induction [24].

\section{$\mathrm{NF}-\boldsymbol{\kappa} \mathbf{B}$}

$\mathrm{NF}-\kappa \mathrm{B}$ is a transcription factor associated with apoptosis. In its inactive state, NF- $\kappa \mathrm{B}$ is bound to $\mathrm{I} \kappa \mathrm{B}$ in the cytoplasm. NF $-\kappa B$ inducers activate NF- $\kappa$ B by degrading I $\kappa$ B, thus freeing NF- $\kappa B$ for translocation to the nucleus [28]. NF$\kappa \mathrm{B}$ can act as both a proapoptotic and anti-apoptotic regulator within the same cell type, and so its specific function is determined by the environment.

NF- $\kappa \mathrm{B}$ upregulates a number of proapoptotic genes, including Fas and death receptors 4,5 , and 6 . In a rat study by Saradha et al., NF- $\kappa \mathrm{B}$ activation peaked within $24 \mathrm{~h}$ of testicular germ cell exposure to lindane, whereas maximal Fas expression did not occur until $72 \mathrm{~h}$ post-exposure. The staggered activity suggests that Fas expression increased in

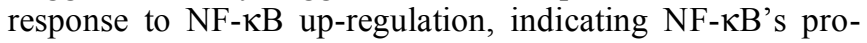
apoptotic function [29].

Previous observations of glucocortoid-induced upregulation of $\mathrm{I} \kappa \mathrm{B}$, as well as mutual antagonism between NF- $\kappa \mathrm{B}$ and glucocorticoid, suggest that $N F-\kappa B$ could act as an inhibiting agent in glucocorticoid-mediated apoptosis. In addition, NF- $\kappa \mathrm{B}$ inhibited CORT-induced apoptosis in rat Leydig cells, as cells overexpressing NF- $\kappa \mathrm{B}$ were less susceptible to CORT-induced apoptosis; cells receiving PDTC, a known NF- $\kappa \mathrm{B}$ inhibitor, underwent higher levels of CORT-induced apoptosis [28]. This suggests that NF-kB acts as an anti-apoptotic agent in receptor-mediated apoptosis.

Testicular NF- $\kappa \mathrm{B}$ responds to MEHP exposure, suggesting the regulatory role of $\mathrm{NF}-\kappa \mathrm{B}$ in germ cell apoptosis. NF$\kappa \mathrm{B}$ subunits showed a variety of localization patterns in rat testis following MEHP exposure. However, elevated activation in spermatocytes was particularly notable, since these germ cells are in the meiotic stage most sensitive to MEHPmediate damage [8].

\section{Mitochondria-Mediated Pathway}

Mitochondrial cell respiration is the main consumer of oxygen, as well as the primary location of endogenous ROS production. Studies of different cell types show that several apoptotic pathways converge on the mitochondrion, which then becomes a key player in continuing the cell death sequence [30-33].

Intracellular stress triggers mitochondrial apoptosis, which is regulated by the $\mathrm{Bcl} 2$ family [23]. Cellular stress results in the release of cytochrome $\mathrm{c}$ from damaged mitochondria. Cellular stress or injury induces interaction between the Bax-like and BH3-only protein families, which permeabilizes the mitochondrial outer membrane and releases apoptotic proteins for diffusion into the cytosol. The release of cytochrome $\mathrm{c}$ and its subsequent interaction with cytosolic protein APAF-1 results in a protein complex called the apoptosome. This oligomer serves as scaffolding for caspase activation, which ultimately leads to apoptosis [22]. The activation of caspase- 9 begins the caspase cascade towards apoptosis [23]. Furthermore, PT induces mitochondrial production of ROS [6].

Non-Bcl-2 family proteins, such as p53, have also been implicated in the regulation of mitochondrial outer membrane permeability. Cytosolic p53 not only localizes to the mitochondria following stress induction, but also antagonizes Bcl2-like protein and directly activates effector proteins.

It has been proposed that mitochondrial disruption is "neither necessary nor sufficient for apoptosis," as recent evidence shows that the caspase cascade can proceed sans cytochrome c release, and certain cells keep surviving for days after a mitochondrial breach [6].

\section{Receptor-Mediated Pathway}

Spermatogenesis is a meticulously regulated process that incorporates autocrine, paracrine, and endocrine signaling. The Fas signal pathway is a critical paracine regulator that comprises Fas ligand (FasL) expressed in Sertoli cells and the Fas receptor expressed in germ cells.

Caspase- 8 and Fas-associated protein with Death Domain (FADD) are both components of DISC, and their interaction activates caspase- 8 [34]. Similarly, when $\mathrm{TNF} \alpha$ binds to TNF-R1 death receptor, TNF-R1 attracts the aggregation of various cytoplasmic signaling proteins, including TNF Receptor-Associated protein with Death Domain (TRADD). Upon interaction with TRADD, TNF-R1 is able to recruit and "unlock" Fas-associated protein with Death Domain (FADD), which in turn recruits procaspases-8 and -10 [6]. Fas signaling regulates NF- $\mathrm{KB}$ transcription, while activated $\mathrm{NF}-\kappa \mathrm{B}$ also regulates Fas transcription [8].

\section{OXIDATIVE DAMAGE IN THE TESTIS}

Oxidative stress (OS) results from excessive biosynthesis or intake of pro-oxidants, impaired biosynthesis of antioxidants, or a combination of both. Balancing pro-oxidants and antioxidants is vital for normal testis function and sperm fertilization ability [7]. Consequently, much focus has been given to reactive oxygen species (ROS), a group of highly reactive oxidizing agents that are able to damage almost all molecular species in spermatozoa, including lipids, proteins and nucleic acids [7, 35]. Whereas low ROS levels are necessary for sperm maturation, high ROS levels wreak OS- 
mediated pathological consequences on spermatozoa, including sperm DNA fragmentation [36] and abnormal sperm morphology [37]. Thus, excessive generation of ROS can cause cellular damage, and impair sperm structure and function.

\section{Spermatogenesis}

Developing spermatozoa undergo a series of maturation processes involving ROS. This growth course involves membrane, nuclear and enzyme-related remodeling, the release, attachment and rearrangement of surface proteins, as well as the assembly of the signal transduction machinery. Aitken et al. demonstrated that ROS act as intracellular signaling molecules to aid proper chromatin packaging and stability [35].

The sperm cell is distinct from other germinal or somatic cells in its ability to generate ROS as well as its great vulnerability to such molecules. Not only do sperm cells contain high levels of polyunsaturated fatty acids and endogenous ROS, but they have a limited store of cytoplasmic defense enzymes that leaves them nearly incapable of membrane repair. Consequently, sperm cells are particularly susceptible to oxidative damage, especially lipid peroxidation. Due to evidence linking excessive ROS synthesis and failed spermoocyte fusion, oxidative stress has been proposed to damage the sperm plasma membrane [38].

Oxidative stress can inflict direct oxidative damage to genomic DNA or up-regulate apoptotic proteins. Either pathway leads to germ cell death and impaired spermatogenesis [39, 40]. Oxidative stress and the release of ROS during spermatogenesis have been linked by many studies to the role of germ cell apoptosis in the testis [41-46].

\section{Steroidogenesis}

Steroidogenesis is the generation of steroid hormones by a variety of tissues in the endocrine system. Among the secreted hormones, testosterone and follicle stimulating hormone (FSH) act concomitantly as the two main regulators of spermatogenesis. Testosterone is an androgen synthesized in Leydig cells under the direction of leutinizing hormone $(\mathrm{LH})$, and is essential for the initiation and progression of normal spermatogenesis. FSH is a glycoprotein synthesized and secreted by gonadotrophs of the anterior pituitary controlled by pulses of gonadotropin-releasing hormone $(\mathrm{GnRH})$. It acts synergistically with LH in stimulating the maturation of germ cells as well as inducing the formation of Sertoli-Sertoli intracellular tight junctions. Both testosterone and FSH bind to target receptors on the Sertoli cells and inhibit death signals sent to germ cells [3, 47].

Serum corticosterones have been reported to induce Leydig cell apoptosis and impair Leydig cell steroidogenesis [48]. Additionally, elevated testosterone levels have been shown to induce germ cell death [49]. Kim et al. demonstrated that testosterone withdrawal induces spermatocyte apoptosis via caspase-3 activation and CAD expression [50]. Therefore, it is critical that normal hormone levels remain intact to ensure properly occurring steroidogenesis.

Studies have suggested various mechanistic pathways in which toxins may inhibit testosterone production [51, 52].
Ronco et al. demonstrated that lindane, an organochlorine pesticide, reduced the production of cAMP, a second messenger in the testicular steroidogenesis pathway [52].

The biosynthesis of steroid hormones from a cholesterol precursor requires oxidative enzymes located in the mitochondria and endoplasmic reticulum. As an oxygen-mediated process, steroidogenesis is particularly vulnerable to ROS-induced damage. Since physiological ROS activity and lipoprotein consumption in the plasma are both essential once steroidogenic cells are stimulated, excessive ROS levels may effect overproduction of steroid hormones and subsequently induce apoptosis [3, 53]. Diemer et al. report that ROS inhibit steroidogenesis in human Leydig cells by targeting hormone-sensitive mitochondrial cholesterol transfer [13].

\section{OS AND TESTICULAR APOPTOSIS: INIMICAL ROLE OF ENVIRONMENTAL TOXINS}

Rising incidence of infertility over the past several decades has snared the attention of scientists and clinicians $[54,55]$. Furthermore, environmental toxins have been welldocumented in their deleterious effects on male reproductive function $[35,40,56]$. Numerous studies implicate such toxicants in inducing DNA fragmentation and chromatin damage and impairing testicular function [56-59]. Much research has focused on oxidative stress: its pathological implications with regards to reproductive health as well as its etiology in environmental toxicants [60].

Environmental contaminants are capable of elevating ROS levels and depleting ROS-scavenging antioxidants. By inducing oxidative imbalance, these compounds alter key processes, such as apoptosis, spermatogenesis and steroidogenesis. Research indicates that common mechanisms include up- or down-regulating the expression of apoptotic related proteins, in addition to directly triggering apoptosis in spermatocytes $[7,61]$. Numerous toxins have been tested to elucidate the mechanistic pathways through which they induce OS-mediated testicular apoptosis. These findings are summarized in Table $\mathbf{1}$.

\section{Alkylphenol Polyethoxylates}

During seminiferous tubule maturation, oestradiol acts synergistically with FSH to support germ cell survival. However, when FSH is deficient or absent, oestradiol has an inhibitory, pro-apoptotic effect [3]. Since estrogen receptors are present in the pituitary and spermatogenic cells, estrogenlike chemicals can act as agonists or antagonists for the hormone, thereby interfering with spermatogenesis [62].

Octylphenol (OP) is a metabolite of alkylphenol polyethoxylates, which are commonly found in industrial processing and in household and institutional cleaning products $[63,64]$. OP is more persistent than its parent compounds, and can mimic naturally produced estrogen by interacting with estrogen receptors [65]. Bian et al. demonstrated that $150 \mathrm{mg} / \mathrm{kg} / \mathrm{d}$ of OP significantly lowered sperm motility; raising the dose to $450 \mathrm{mg} / \mathrm{kg} / \mathrm{d}$ also significantly decreased testicular sperm count and daily sperm production [66].

Blake et al. demonstrated that chronic administration of 4-tert-octylphenol (OP) to adult male rats resulted in lower 
Table 1. Summary of OS-Mediated Mechanisms of Environmentally Induced Apoptosis, by Toxin

\begin{tabular}{|c|c|c|c|c|}
\hline Compound & Study & Cells Observed & Genes/Proteins Involved & Proposed Mechanisms \\
\hline \multirow[t]{2}{*}{$\begin{array}{l}\text { Octylphenol } \\
{[50,63,100]}\end{array}$} & Mishra et al. & Germ & $\uparrow$ FasL, $\uparrow$ cyt c & Fas-signaling pathway, mitochondrial pathway \\
\hline & Qian et al. & Sertoli & $\begin{array}{l}\uparrow \text { Bax, } \downarrow \text { Bcl- } 2, \downarrow \text { downstream } \\
\text { Fas/FasL effector }\end{array}$ & $\begin{array}{l}\text { Altering Bcl-2/Bax ratio activates mitochondrial } \\
\text { pathway }\end{array}$ \\
\hline Nonylphenol [72] & Han et al. & Sertoli & $\uparrow$ Fas, $\uparrow$ FasL & $\begin{array}{l}\text { Direct cell damage followed by compensatory } \\
\text { activation of Fas-signaling pathway }\end{array}$ \\
\hline $\begin{array}{l}\text { Polycyclic aromatic } \\
\text { hydrocarbons [74] }\end{array}$ & Coutts et al. & Germ & $\uparrow B a x, \uparrow P A R P$ cleveage & Mitochondrial pathway \\
\hline Bisphenol A [76; 78] & Li et al. & Germ, Leydig & $\uparrow$ Fas, $\uparrow$ FasL, $\uparrow$ caspase- 3 & $\begin{array}{l}\text { Fas-signaling pathway triggers Leydig cell } \\
\text { apoptosis that then induces germ cell apoptosis }\end{array}$ \\
\hline $\begin{array}{l}\text { Polychlorinated } \\
\text { biphenyls [38] }\end{array}$ & Hsu et al. & Germ & $\begin{array}{c}\uparrow \text { caspase- } 3, \uparrow \text { caspase- } 9, \downarrow \text { Fas } \\
\downarrow \text { Bax }, \downarrow \text { Bcl- } 2, \downarrow \text { p } 53\end{array}$ & Activation of caspase cascade \\
\hline Lindane [29] & $\begin{array}{l}\text { Saradha et } \\
\text { al.(2009) }\end{array}$ & Germ & $\begin{array}{c}\uparrow \text { cyt } c, \uparrow \text { caspase- } 9, \uparrow \text { caspase- } 3 \text {, } \\
\uparrow \text { Fas, } \uparrow \text { FasL }\end{array}$ & Mitochondrial pathway, Fas-signaling pathway \\
\hline Methoxychlor [89] & $\begin{array}{l}\text { Vaithinathan et } \\
\text { al. }\end{array}$ & Germ & $\uparrow$ Fas, $\uparrow$ FasL,$\uparrow$ caspase- $3, \downarrow$ NF- $\kappa \mathrm{B}$ & $\begin{array}{l}\text { Mitochondria and FasL-mediated signaling } \\
\text { pathway }\end{array}$ \\
\hline \multirow[t]{2}{*}{ Toluene [91] } & $\begin{array}{l}\text { El-Nabi Kamel } \\
\quad \text { et al. }\end{array}$ & Germ & $\leftrightarrow$ caspase-3 & Inconclusive \\
\hline & Yilmaz et al. & Leydig & $\downarrow$ testosterone & Inconclusive \\
\hline $\begin{array}{l}\text { tert-Butyl } \\
\text { hydroperoxide [94] }\end{array}$ & Kalia et al. & Germ & $\uparrow \mathrm{p} 53, \uparrow \mathrm{p} 21$ & $\begin{array}{l}\mathrm{p} 53 \text { and } \mathrm{p} 21 \text { upregulation trans-activates Bcl-2 } \\
\text { family proteins }\end{array}$ \\
\hline $\begin{array}{l}\text { 1,3-Dinitrobenzene } \\
\text { (1,3-DNB) [101] }\end{array}$ & Lee et al. & Germ & $\uparrow \mathrm{Bax}, \downarrow \mathrm{Bcl}-2$ & $\begin{array}{c}\text { Alteration of Bcl-2/Bax ratio triggers mitocondrial } \\
\text { pathway }\end{array}$ \\
\hline Nitrobenzene [102] & Richburg et al. & Germ & & \\
\hline \multirow[t]{2}{*}{ Ethanol [104-105] } & Koh & & $\downarrow$ pAkt, $\downarrow$ pErk $1 / 2, \downarrow$ Bad & Suppression of survival-signaling pathway \\
\hline & Hu et al. & Germ & $\uparrow$ FasL & Fas-signaling pathway \\
\hline
\end{tabular}

levels of LH, FSH, prolactin and testosterone, and proposed that OP inhibited the secretion of reproductive hormones by mimicking estrogen [67].

An in vitro study by Mishra et al. indicates a link between increased estrogen exposure and sperm cell death [68]. The results suggest that FasL upregulation mediates estrogen-induced apoptosis in cells of spermatogenic lineage [68]. The study also suggests that estradiol exposure amplifies the death-inducing signal via mitochondrial release of cytochrome c [68]. This experiment was significant in establishing the importance of the independent capability of cells of the spermatogenic lineage to respond to estrogens, as well as suggesting that low dose estrogen can potentially result in severe spermatogenic cellular dysfunction without interfering with the hypothalamo-hypophyseal axis [68].

Qian et al. demonstrated that apoptosis caused the reduction of rat Sertoli cell viability following OP treatment, as evidenced by cellular shrinkage, chromatin condensation, and DNA cleavage and fragmentation. Results showed that OP up-regulated Bax protein and down-regulated $\mathrm{Bcl}-2$ protein, which together led to activation of the caspase-3 pathway. Furthermore, the study noted that OP downregulated a downstream effector of the Fas/FasL pathway, suggesting the involvement of Fas/FasL [63]. Researchers 
speculate that alkylphenols such as OP activate apoptosis by inhibiting $\mathrm{ER} \mathrm{Ca}^{2+}$ pumps in the testis, activating Fassignaling pathways, or mediating Bcl-2/Bax levels.

An in vitro study by Kim et al. looked at the effects of OP on the testicular development of prepubertal rats [69]. OP administration resulted in a marked increase in the occurrence of apoptosis in testicular germ cells. This was accompanied by a corresponding decrease in bcl-xL mRNA expression, although bcl-2 and bax mRNA expressions did not demonstrate any substantial change [69]. These results illustrate the ability of OP to severely reduce the size and/or impair the function of the male reproductive organs by increasing apoptosis of testicular germ cells [69].

In addition, Zhou et al. examined the role of apoptosis related $\mathrm{Fas} / \mathrm{FasL}$ in azoospermia or oligozoosprmia induced by testosterone undecanoate [70]. The researchers speculated that the Fas system may initiate and regulate the germ cell apoptosis induced by testosterone undecanoate [70].

Nonylphenols (NP) are used in industrial and household detergents, cosmetic products, and spermicides. Also found as water contaminants, they accumulate in fish and pose a hazard to successively higher vertebrates on the food chain. Low micromolar concentrations of NP have been shown to induce testicular oxidative stress and cytotoxicity in vitro. Exposing rat Sertoli cells to $40 \mu \mathrm{M}$ NP, Gong et al. observed significant increases in the levels of intracellular ROS and lipid peroxidation markers [71].

Han et al. showed that NP induced Sertoli cell apoptosis in rats. Observing increased $\mathrm{Fas} / \mathrm{FasL}$ gene expression following direct Sertoli cell injury, the researchers proposed that the upregulation indicated a response by the Fas/FasL system to recover the Sertoli cells' support capacity [72].

\section{Polycyclic Aromatic Hydrocarbons}

Polycyclic aromatic hydrocarbons (PAHs) are environmental pollutants that are mainly produced during fuel combustion [73]. PAHs can ligate and activate aryl hydrocarbon receptors (AHRs), which are transcription factors involved in regulating xenobiotic metabolism, and are selectively expressed in solely the germ cells in the first- and secondtrimester human fetus [74].

Coutts et al. demonstrated that PAHs induced germ cell apoptosis by interacting with the AHR receptor. PAH exposure stimulated Bax expression and PARP cleavage in human fetal testes, while an AHR antagonist neutralized these effects [74].

\section{Bisphenol A (BPA)}

Bisphenol A (BPA) is a known environmental estrogen that is most commonly used to produce polycarbonate plastic. Found in the lining of food and beverage cans, as dental sealants, and as an additive to other consumer products, the resin can leach out if exposed to heat or acidic/basic compounds that hydrolyze its ester bonds [75].

High-dose BPA treatment was shown to upregulate FasL gene expression in rat Sertoli cells [76]. Another study showed that BPA altered the expression and localization of cell junctional proteins derived from a Sertoli cell line [77].
High doses of BPA led to concomitant Leydig and germ cell apoptosis in pubertal mice. Furthermore, Li et al. observed translocalized expression of Fas and active caspase-3 in these same cell types as apoptosis occurred, in addition to transactivation of Fas, FasL, and active caspase-3. The authors hypothesized that BPA exposure leads to germ cell apoptosis by inducing Leydig cell loss [76].

Another possible mechanism of germ cell apoptosis is direct cell damage, as Takahashi and Oishi found that BPA caused dose-related degeneration of late spermatids and seminiferous tubules without affecting serine testosterone levels [78].

\section{Polychlorinated Biphenyls (PCB)}

Polychlorinated biphenyls (PCBs) lead to oxidative stress when PCB metabolites oxidize into quinines and semiquinones, which act via free radicals to inflict oxidative damage on DNA [38]. Hsu et al. observed a bimodal effect on the expression of apoptotic genes and their protein products: low doses of PCB induced p53 gene expression and down-regulated caspase-3, whereas high doses downregulated the gene expressions of Fas, Bax, bcl-2, and p53 and induced activation of caspase- 3 and -9 . Thus, researchers hypothesize that low-dose PCB treatment causes p53 to impair spermatogenesis by initiating cell cycle arrest, whereas high-dose PCB exposure is believed to lead to apoptosis by activating the caspase cascade [38].

\section{Lindane}

In rats, lindane collects in the testis and deleteriously alters germinal epithelium and Sertoli cell fragmentation [29].

After treating adult rats with a single oral dose of lindane, Saradha et al. evaluated testicular levels of cytochrome c, a mitochondria-associated intermediate of apoptosis, and caspase-9, an upstream initiator of the mitochondrial signaling cascade for cell death. The study demonstrated a significant increase from control levels, even when amounts of cytochrome c and caspase-9 had dropped at the end of the 72h observation period [29].

Additionally, the lindane treatment produced significant, time-dependent increases in the testicular levels of caspase3 , Fas and FasL from $6 \mathrm{~h}$ to $72 \mathrm{~h}$ post-exposure. Immunofluorescence microscopy showed that caspase-3 and Fas colocalized in the peritubular germ cells of lindane-treated rat testis. Moreover, FasL was concentrated in the cytoplasmic extensions of Sertoli cells and the peritubular germ cells following lindane exposure [29].

Cytochrome c and caspase- 9 decreased at $72 \mathrm{~h}$ posttreatment, while caspase 3 showed continual increase. This is consistent with the mitochondrial apoptosis pathway, as cytochrome $c$ and caspase- 9 act upstream whereas caspase-3 is the main downstream effector in the caspase cascade. Similarly Fas and FasL levels rose significantly in parallel, and peaked at the $72 \mathrm{~h}$ point [79].

Numerous studies have linked oxidative stress and ROS with lindane's harmful effects on testicular function $[29,46]$. In the abovementioned study by Saradha et al., maximal increases in cytochrome $\mathrm{c}$ and caspase- 9 levels at $12 \mathrm{~h}$ and 
$24 \mathrm{~h}$ post-exposure corresponded to the time points at which transient elevation in $\mathrm{H} 2 \mathrm{O} 2$ levels had previously been observed [80]. Within $12 \mathrm{~h}$ of exposing rat testis to a single dose of lindane, Saradha et al. observed the induction of oxidative stress $[80,29]$.

\section{Methoxychlor}

Methoxychlor is a broad-spectrum chlorinated insecticide that is used extensively for controlling insects on agricultural crops, livestock, animal feeds, barns, pets, and in residential gardens. Methoxychlor is an atypical environmental estrogen. It binds to recombinant human ER $\alpha$ and $\operatorname{ER} \beta$ with a relative binding affinity that is 10,000 times less than $17 \beta$ estradiol [81] and stimulates the transcriptional activity of both estrogen receptor subtypes, in vitro, at concentrations of approximately $1000 \mathrm{nM}[81,82]$. More recently, it was reported that transient embryonic exposure to methoxychlor during a critical time of gestation reduced spermatogenic capacity in the testes of adult male rats of subsequent generations $[83,84]$. Treatment of pregnant female rats with methoxychlor from embryonic day 8 to 15 at dosages of 100 and $200 \mathrm{mg} / \mathrm{kg} /$ day increased spermatogenic cell apoptosis and decreased sperm number and motility in adult animals of the $F_{1}$ and $F_{2}$ generations [83]. Studies from our laboratory has also demonstrated a state of oxidative stress induced in adult rat testis following short and long term exposure of methoxychlor shows that oxidative stress is induced by promoting lipid peroxidation, and a decrease in the activity of antioxidant enzymes in testis and epididymis $[44,85,86]$. Recently, we have demonstrated a transient inhibitory effect of methoxychlor (50 mg/ kg body weight) on testicular steroidogenic enzymes, $\Delta^{5} 3 \beta$-hydroxysteroid dehydrogenase and $\Delta^{5} 17 \beta$-hydroxysteroid dehydrogenase within $6-12 \mathrm{~h}$ of exposure and a possible role of hydrogen peroxide $\left(\mathrm{H}_{2} \mathrm{O}_{2}\right)$ in mediating these effects was suggested [87]. Methoxychlor showed alteration in the levels of heat shock protein and clusterin accompanied by an induction of oxidative stress in the testis at a same dose [88]. In another study, exposure to a single dose of methoxychlor at $50 \mathrm{mg} / \mathrm{kg}$ body weight induced apoptosis in male rat germ cells in a time-dependent manner via mitochondrial mediated and FasL-dependent pathways [89].

\section{Toluene}

Toluene is an organic solvent present in plastics, adhesives, paints, varnishes, and inks. When Nakai et al. treated rats with toluene, reduced epididymal sperm counts and serine testosterone concentration were associated with elevated testicular 8-oxodG levels; meanwhile, GnRH mRNA levels remained unchanged. As 8-oxodG indicates oxidative DNA damage, the authors concluded that toluene's toxicity is derived not from endocrine disruption, but direct oxidative damage of spermatozoa [90].

El-Nabi Kamel and Shehata implicated toluene in altering the redox state and triggering oxidative stress in the testis, but observed no postexposure change in testicular caspase-3 activity [91]. Furthermore, prolonged oral toluene exposure at the common abuse density in rats did not reduce testicular weight, nor did it significantly alter spermatogenesis [92]. However, Yilmaz et al. observed that toluene inhalation significantly lowered testicular weight and seminiferous tubule diameters, and immunostaining showed that serine testosterone levels in Leydig cells had dropped significantly [93]. While toluene is an established generator of oxidative damage, it remains inconclusive as to whether toluene's toxicity extends to inducing apoptosis, and whether toluene targets spermatogenesis or steroidogenesis.

\section{tert-Butyl Hydroperoxide (tBHP)}

tert-Butyl hydroperoxide (tBHP) decomposition involves the release of superoxide or superoxide-like radicals, which can then degrade the cellular membrane [94]. In a study that administered tBHP to mice, Kaur et al linked a decrease in sperm parameters to increased lipid peroxidation. These changes indicate that tBHP-induced OS impairs spermatogenesis. tBHP treatment upregulated NF-kB transcripts p65 and p50, as well as NF-kB-regulated antioxidant enzymes. The study demonstrated that NF-kB regulates antioxidant enzyme GSH-Px through direct trans-activation. Together these findings suggest that the testicular response mechanism to tBHP-generated OS is to alter NF-kB's antioxidant enzyme gene regulation [95].

In a study by Kalia et al., tBHP treatment led to significant elevation of ROS production, germ cell damage, and DNA degradation in rat testes. Furthermore, there were significant increases in mRNA and protein expression of p53 and $\mathrm{p} 21$, which were localized to different spermatogenesis stages [94]. While p21 is best known for regulating cell cycle arrest, it also displays proapoptotic function by upregulating Bax protein when overexpressed [96]. The observed association between p53 upregulation and ROS generation in tBHP-treated mice demonstrated that tBHP induces an apoptotic pathway, mediated by OS, that involves p53 [94].

\section{Phthalates}

Phthalates are ubiquitous chemical compounds used as plasticizers for plastic devices, food packaging, blood storage bags, and medical tubing [97]. Recently conducted studies have verified that phthalates, are capable of generating severe germ cell apoptosis [98, 99]. Apoptosis occurred with significantly less frequency in FasL knockout mice than in wild-type mice, implicating the Fas system in phthalateinduced germ cell apoptosis [8].

In in vitro and in vivo experiments, Yao et al. demonstrated that mono-(2-ethylhexyl) phthalate (MEHP) can trigger germ cell apoptosis by increasing Sertoli cell FasL transcription both directly and indirectly. In the direct mechanism, Sertoli cells activate NF-kB following MEHP exposure. In the complementing pathway of action, MEHP injures Sertoli cells and consequently weakens the structural, hormonal, and nutritive support that germ cells normally receive. As a result, germ cells secrete soluble tumor necrosis factor alpha $(\mathrm{sTNF} \alpha)$ as a paracrine factor to activate the NF-kB signaling pathway in Sertoli cells. Triggering NF-kB upregulates Sertoli cell FasL expression, which promotes pro-apoptoic interaction with germ cellexpressed Fas receptor [99].

Kasahara et al. implicated oxidative stress in overseeing (DEHP)-induced testicular atrophy. In an in vivo rat study, 1 $\mathrm{g} / \mathrm{kg}$ DEHP was the minimal dose needed to induce sperm- 
atocyte apoptosis, elevate ROS generation and selectively reduce antioxidant levels in the testis. Notably, the authors discovered a significant increase in cytochrome $c$ levels that coincided with the transformation of DEHP into MEHP. Since the observed MEHP concentrations sufficed for superoxide radical generation, the authors concluded that DEHP metabolism induced oxidative stress in and around the mitochondria. The ensuing release of cytochrome $\mathrm{c}$ began the series of events leading to apoptosis [97].

\section{2,5-Hexanedione (2,5-HD)}

2,5-Hexanedione (2,5-HD), a metabolite of the common industrial solvents $n$-hexane and methyl $n$-butyl ketone, is able to trigger apoptosis in male germ cells [100]. In an in vitro study by Mishra et al., 2,5-HD treatment produced apoptosis in approximately 50 percent of the cells $8 \mathrm{~h}$ postexposure [100]. The study also identified evidence for the cleavage of poly (ADP-ribose) polymerase (PARP), which is a caspase-3 3 substrate, $6 \mathrm{~h}$ following 2,5-HD administration [100].

Additionally, Mishra et al. demonstrated that 2,5-HD exposure in vitro caused a significant increase in testicular ROS with a subsequent elevation in intracellular calcium $\left(\mathrm{Ca}^{2+}\right)$ levels. The rise in intracellular $\mathrm{Ca}^{2+}$ produced an elevation in Bcl-xS levels relative to Bcl-xL levels. However, since 2,5-HD did not alter levels of Bcl-2 and Bax, 2,5-HD's cytotoxic impact may be mediated by inversing the ratio between pro- and anti-apoptosis $\mathrm{Bcl}-2$ family proteins. Furthermore, cytosolic accumulation of cytochrome c indicated cells had activated the mitochondrial pathway of cell death [100].

\section{1,3-dinitrobenzene (1,3-DNB)}

1,3-Dinitrobenzene $(1,3-\mathrm{DNB})$ is a highly reactive nitroaromatic compound that is incorporated in the manufacture of polymers, pesticides, and dyes [101]. This reactive nitrogen species (RNS) acts similar to ROS, damaging nearby cells if present in excess.

Previous rat research demonstrated that 1,3-DNB injured Sertoli cells and induced apoptosis in surrounding germinal cells [101]. Studying rat protein expression levels following 1,3-DNB treatment, Lee et al. (2009) observed down-regulation of the pro-survival protein Bcl-2, and up-regulation of the pro-apoptotic protein Bax. Although the ability of 1,3DNB to inflict apoptosis has been well documented, there is limited information pertaining to the mechanistic pathways of cell death in Sertoli cells [101].

\section{Nitrobenzene}

Nitrobenzene (NB) is a component of rubber, pesticides and pharmaceuticals, and acts as a toxicant by elevating the occurrence of testicular apoptosis [102]. Allenby et al. assessed the effect of $\mathrm{NB}$ on Sertoli cells in vitro and concluded that NB toxicity may disrupt Sertoli cell function [103].

Richburg et al. evaluated the sensitivity of testicular germ cells to NB [102]. Whereas activation of the Fassignaling pathway is widely thought to be the mechanism through which toxicant-induced Sertoli cell injury results in germ cell apoptosis, results indicated that Fas-mediated signaling is not required for NB-induced germ cell apoptosis. Rather, a dysfunctional Fas signaling system sensitized the mice to NB-induced germ cell death [102].

\section{Ethanol}

Ethanol, a well-known environmental compound, affects the testis by disrupting the hypothalamic-pituitary-gonadal axis and hampering the secretory function of the Sertoli cells $[27,104]$. In a rat study by Koh, ethanol suppressed testicular survival-signaling pathways by reducing levels of activated survival kinases, including pAkt and pErk1/2, and phosphorylated Bad at Ser112 and Ser136 [105]. Koh hypothesized that ethanol induced apoptotic cell death by suppressing the activation of survival kinases and the phosphorylation of their downstream targets [27].

$\mathrm{Hu}$ et al. further noted that chronic exposure to ethanol could result in testicular germ cell apoptosis [104]. In an in vitro transgenic mouse model, histopathological examination revealed that acute ethanol exposure produced epithelial degeneration of seminiferous tubules in FasL-overexpressing mice, whereas wild-type mice experienced no change in testicular morphology. These results suggested that FasL expression determines the sensitivity of testes to ethanol in mice, and that the Fas ligand mediates apoptosis of testicular germ cells [104].

\section{EXPERT COMMENTARY}

The aim of this article is to elucidate the mechanism(s) of environmental toxicant induced apoptosis in male reproduction. Environmental contaminant exposure can cause oxidative stress in the testis, leading to apoptosis in germ, Sertoli, and Leydig cells. Numerous studies have identified the pathways through which specific toxicants trigger OSinduced testicular apoptosis. This information is relevant for preventive of environmental and occupational hazards, as it further evidences the need for reduced exposure to environmental contaminants.

\section{FIVE-YEAR REVIEW}

In the existing scenario of massive industrialization and changing life styles, more focus should be on identification of populations at risk, evaluation of reproductive hazards, understanding the mechanism of action and to devise an appropriate preventive or intervention strategies to improve public health. Research on reproduction is complicated due to various constraints involved in evaluating and interpreting reproductive outcomes as the biology of reproduction is complex and the effect is not confined to the target alone.

\section{KEY POINTS}

- $\quad$ Spermatogenesis generates ROS under physiological conditions that have regulatory influence on germ cell apoptosis.

- $\quad$ Toxicants induce massive germ cell death either by increasing the expression of apoptosis related proteins or by oxidative imbalance. 
- Identifying the environmental contaminants that pose a major burden to the general population and prioritizing the agents that require intensive research could help in finding the hazards caused by environmental contaminants.

\section{ABBREVIATIONS}

\begin{tabular}{|c|c|c|}
\hline 1,3-DNB & $=$ & 1,3-Dinitrobenzene \\
\hline 2,5-HD & $=$ & 2,5-Hexanedione \\
\hline AHR & $=$ & Aryl hydrocarbon receptor \\
\hline BPA & $=$ & Bisphenol A \\
\hline CARD & $=$ & Caspase recruitment domain \\
\hline DED & $=$ & Death effector domain \\
\hline DEHP & $=$ & di-(2-ethylhexyl) phthalate \\
\hline DISC & $=$ & Death inducing signaling complex \\
\hline FADD & $=$ & Fas-associated protein with Death Domain \\
\hline EDS & $=$ & Ethylene dimethanesulfonate \\
\hline FasL & $=$ & Fas ligand \\
\hline FSH & $=$ & Follicle stimulating hormone \\
\hline GnRH & $=$ & Gonadotropin-releasing hormone \\
\hline GST & $=$ & Glutathione- $S$-transferase \\
\hline $\mathrm{hCG}$ & $=$ & Human chorionic gonadatropin \\
\hline $\mathrm{LH}$ & $=$ & Leutinizing hormone \\
\hline MEHP & $=$ & Mono-(2-ethylhexyl) phthalate \\
\hline NB & $=$ & Nitrobenzene \\
\hline NP & $=$ & Nonylphenol \\
\hline $\mathrm{OP}$ & $=$ & Octylphenol \\
\hline OS & $=$ & Oxidative stress \\
\hline PCB & $=$ & Polychlorinated biphenyl \\
\hline ROS & $=$ & Reactive oxygen species \\
\hline sTNF $\alpha$ & $=$ & Soluble tumor necrosis factor alpha \\
\hline tBHP & $=$ & tert-butyl hyroperoxide \\
\hline TRADD & & $\begin{array}{l}\text { TNF Receptor-Associated protein with } \\
\text { Death Domain }\end{array}$ \\
\hline
\end{tabular}

\section{ACKNOWLEDGEMENT}

P. P. Mathur acknowledges the receipt of financial support from the Department of Science and Technology, Government of India under the projects 1) SP/SO/B-65/99 2) DST-FIST 2009 3) Indian Council of Medical Research, New Delhi 4) Department of Biotechnology, New Delhi 5) Department of Information Technology, New Delhi for Centre of excellence in Bioinformatics. The authors also thank the staff of Bioinformatics Center, Pondicherry University, Pondicherry for providing various facilities.

\section{CONFLICT OF INTEREST}

None Declared.

\section{REFERENCES}

[1] Vaithinathan S, Saradha B, D'Cruz SC, Mathur PP. Apoptosis in testis: The hostile role of environmental toxicants. In: Sharma RS, Ranna A, Rajalakshmi M, Eds. Recent Advances and Challenges in Reproductive Health Research. New Delhi: Indian Council of Medical Research 2008; pp. 293-305.

[2] Martincic DS, Virant Klun I, Zorn B, Vrtovec HM. Germ cell apoptosis in the human testis. Pflugers Arch 2001; 442: 159-60.

[3] Shaha C, Tripathi R, Mishra DP. Male germ cell apoptosis: regulation and biology. Philos Trans R Soc Lond B Biol Sci 2010; 365: 1501-15.

[4] Wang X, Sharma RK, Sikka SC, Thomas AJ, Falcone T, Agarwal A. Oxidative stress is associated with increased apoptosis leading to spermatozoa DNA damage in patients with male factor infertility. Fertil Steril 2003; 80: 531-5.

[5] Jacobson MD, Weil M, Raff MC. Programmed cell death in animal development. Cell 1997; 88: 347-54.

[6] Sinha Hikim AP, Swerdloff RS. Hormonal and genetic control of germ cell apoptosis in the testis. Rev Reprod 1999; 4: 38-47.

[7] Mathur PP, Saradha B, Vaithinathan S. Impact of environmental toxicants on testicular function. Immunology, Endocrine and Metabolic Agents Med Chem 2008; 8: 79-90.

[8] Rasoulpour RJ, Boekelheide K. NF-kappaB is activated in the rat testis following exposure to mono-(2-ethylhexyl) phthalate. Biol Reprod 2005; 72: 479-86.

[9] Lizama C, Alfaro I, Reyes JG, Moreno RD. Up-regulation of CD95 (Apo-1/Fas) is associated with spermatocyte apoptosis during the first round of spermatogenesis in the rat. Apoptosis 2007; 12: 499512.

[10] Print CG, Loveland KL. Germ cell suicide: new insights into apoptosis during spermatogenesis. Bioessays 2000; 22: 423-30.

[11] Aggarwal A, Misro MM, Maheshwari A, Sehgal N, Nandan D. Adverse effects associated with persistent stimulation of Leydig cells with hCG in vitro. Mol Reprod Dev 2009; 76: 1076-83.

[12] Aycan Z, Ustunsalih-Inan Y, Cetinkaya E, Vidinlisan S, Ornek A. Evaluation of low-dose hCG treatment for cryptorchidism. Turk J Pediatr 2006; 48: 228-31.

[13] Diemer T, Allen JA, Hales KH, Hales DB. Reactive oxygen disrupts mitochondria in MA-10 tumor Leydig cells and inhibits steroidogenic acute regulatory (StAR) protein and steroidogenesis. Endocrinology 2003; 144: 2882-91.

[14] Yi CH, Yuan J. The Jekyll and Hyde functions of caspases. Dev Cell 2009; 16: 21-34.

[15] Chinnaiyan AM , Dixit VM. The cell-death machine. Curr Biol 1996; 6: 555-62.

[16] Mathieu J, Flexor M, Lanotte M, Besancoz F. A PARP-1/JNK1 cascade participates in the synergistic apoptotic effect of TNFalpha and all-trans retinoic acid in APL cells. Oncogene 2008; 27: 336170.

[17] Mashima T, Naito M, Noguchi K, Miller DK, Nicholson DW, Tsuruo T. Actin cleavage by CPP-32/apopain during the development of apoptosis. Oncogene 1997; 14: 1007-12.

[18] Takahashi A, Alnemri ES, Lazebnik YA, et al. Cleavage of lamin A by Mch2 alpha but not CPP32: multiple interleukin 1 betaconverting enzyme-related proteases with distinct substrate recognition properties are active in apoptosis. Proc Natl Acad Sci USA 1996; 93: 8395-400.

[19] Tewari M, Quan LT, O'Rourke K, et al. Yama/CPP32 beta, a mammalian homolog of CED-3, is a CrmA-inhibitable protease that cleaves the death substrate poly(ADP-ribose) polymerase. Cell 1995; 81: 801-9.

[20] Enari M, Sakahira H, Yokoyama H, Okawa K, Iwamatsu A, Nagata S. A caspase-activated DNase that degrades DNA during apoptosis, and its inhibitor ICAD. Nature 1998; 391: 43-50.

[21] Liu X, Li P, Widlak P, et al. The 40-kDa subunit of DNA fragmentation factor induces DNA fragmentation and chromatin condensation during apoptosis. Proc Natl Acad Sci USA 1998; 95: 8461-6.

[22] Chipuk JE, Moldoveanu T, Llambi F, Parsons MJ, Green DR. The BCL-2 family reunion. Mol Cell 2010; 37: 299-310.

[23] Cory S, Adams JM. The Bcl2 family: regulators of the cellular lifeor-death switch. Nat Rev Cancer 2002; 2: 647-56.

[24] Hemann MT, Lowe SW. The p53-Bcl-2 connection. Cell Death Differ 2006; 13: 1256-9.

[25] Vogelstein B, Lane D, Levine AJ. Surfing the p53 network. Nature 2000; 408: 307-10 
[26] Chao C, Saito S, Kang J, Anderson CW, Appella E, Xu Y. p53 transcriptional activity is essential for $\mathrm{p} 53$-dependent apoptosis following DNA damage. EMBO J 2000; 19: 4967-75.

[27] Kho PS, Wang Z, Zhuang L, et al. p53-regulated transcriptional program associated with genotoxic stress-induced apoptosis. J Biol Chem 2004; 279: 21183-92.

[28] Wang Q, Gao HB. Involvement of nuclear factor-kappa B on corticosterone- induced rat Leydig cell apoptosis. Asian J Androl 2006; 8: 693-702.

[29] Saradha B, Vaithinathan S, Mathur PP. Lindane induces testicular apoptosis in adult Wistar rats through the involvement of Fas-FasL and mitochondria-dependent pathways. Toxicology 2009; 255: 131-9.

[30] Kroemer G. The proto-oncogene Bcl-2 and its role in regulating apoptosis. Nat Med 1997; 3: 614-20.

[31] Kroemer G, Zamzami N, Susin SA. Mitochondrial control of apoptosis. Immunol Today 1997; 18: 44-51.

[32] Marzo I, Brenner C, Zamzami N, et al. The permeability transition pore complex: a target for apoptosis regulation by caspases and bcl2-related proteins. J Exp Med 1998; 187: 1261-71.

[33] Reed JC. Cytochrome c: can't live with it--can't live without it. Cell 1997; 91: 559-62.

[34] Peter ME. The trail discussion: It is FADD and caspase-8! Cell Death Differ 2000; 7: 759-60.

[35] Aitken RJ, Ryan AL, Baker MA, McLaughlin EA. Redox activity associated with the maturation and capacitation of mammalian spermatozoa. Free Radic Biol Med 2004; 36: 994-1010.

[36] Kemal Duru N, Morshedi M, Oehninger S. Effects of hydrogen peroxide on DNA and plasma membrane integrity of human spermatozoa. Fertil Steril 2000; 74: 1200-7.

[37] Aziz N, Saleh RA, Sharma RK, Lewis-Jones I, Esfandiari N, Thomas AJ, Agarwal A. Novel association between sperm reactive oxygen species production, sperm morphological defects, and the sperm deformity index. Fertil Steril 2004; 81: 349-54.

[38] Hsu PC, Pan MH, Li LA, Chen CJ, Tsai SS, Guo YL. Exposure in utero to 2,2',3,3',4,6'-hexachlorobiphenyl (PCB 132) impairs sperm function and alters testicular apoptosis-related gene expression in rat offspring. Toxicol Appl Pharmacol 2007; 221: 68-75.

[39] Abdollahi M, Ranjbar A, Shadnia S, Nikfar S, Rezaie A. Pesticides and oxidative stress: a review. Med Sci Monit 2004; 10: RA141-7.

[40] Saradha B, Mathur PP. Effect of environmental contaminants on male reproduction. Environ Toxicol Pharmacol 2006; 21:34-41.

[41] Chitra KC, Mathur PP. Vitamin E prevents nonylphenol-induced oxidative stress in testis of rats. Indian J Exp Biol 2004; 42: 220-3.

[42] Doreswamy K, Shrilatha B, Rajeshkumar TM. Nickel-induced oxidative stress in testis of mice: evidence of DNA damage and genotoxic effects. J Androl 2004; 25: 996-1003.

[43] Erkkila K, Pentikainen V, Wikstrom M, Parvinen M, Dunkel L. Partial oxygen pressure and mitochondrial permeability transition affect germ cell apoptosis in the human testis. J Clin Endocrinol Metab 1999; 84: 4253-9.

[44] Latchoumycandane C, Mathur PP. Induction of oxidative stress in the rat testis after short-term exposure to the organochlorine pesticide methoxychlor. Arch Toxicol 2002; 76: 692-8.

[45] Samanta L, Roy A, Chainy GB. Changes in rat testicular antioxidant defence profile as a function of age and its impairment by hexachlorocyclohexane during critical stages of maturation. Andrologia 1999; 31: 83-90.

[46] Sujatha R, Chitra KC, Latchoumycandane C, Mathur PP. Effect of lindane on testicular antioxidant system and steroidogenic enzymes in adult rats. Asian J Androl 2001; 3: 135-8.

[47] Pareek TK, Joshi AR, Sanyal A, Dighe RR. Insights into male germ cell apoptosis due to depletion of gonadotropins caused by GnRH antagonists. Apoptosis 2007; 12: 1085-100.

[48] Gao HB, Tong MH, Hu YQ, et al. Mechanisms of glucocorticoidinduced Leydig cell apoptosis. Mol Cell Endocrinol 2003; 199: 153-63.

[49] Tesarik J, Martinez F, Rienzi L, et al. In-vitro effects of FSH and testosterone withdrawal on caspase activation and DNA fragmentation in different cell types of human seminiferous epithelium. Hum Reprod 2002; 17: 1811-9.

[50] Kim JM, Ghosh SR, Weil AC, Zirkin BR. Caspase-3 and caspaseactivated deoxyribonuclease are associated with testicular germ cell apoptosis resulting from reduced intratesticular testosterone. Endocrinology 2001; 142:3809-16.
[51] Nakajima Y, Sato G, Ohno S, Nakajin S. Tributyltin chloride suppresses the P450cl7 transcription involved in testosterone production induced by gonadotropin stimulation in cultured pig Leydig cells. Environ Toxicol Pharmacol 2005; 20: 11-17.

[52] Ronco AM, Valdes K, Marcus D, Llanos M. The mechanism for lindane-induced inhibition of steroidogenesis in cultured rat Leydig cells. Toxicology 2001; 159: 99-106.

[53] Sofikitis N, Giotitsas N, Tsounapi P, Baltogiannis D, Giannakis D, Pardalidis N. Hormonal regulation of spermatogenesis and spermiogenesis. J Steroid Biochem Mol Biol 2008; 109: 323-30.

[54] Kumar S. Occupational exposure associated with reproductive dysfunction. J Occup Health 2004; 46: 1-19.

[55] Saleh RA, Agarwal A. Oxidative stress and male infertility: from research bench to clinical practice. J Androl 2002; 23: 737-52.

[56] Irvine DS. Male reproductive health: cause for concern? Andrologia 2000; 32: 195-208.

[57] Auger J, Kunstmann JM, Czyglik F, Jouannet P. Decline in semen quality among fertile men in Paris during the past 20 years. N Engl J Med 1995; 332: 281-5.

[58] Carlsen E, Giwercman A, Keiding N, Skakkebaek NE. Evidence for decreasing quality of semen during past 50 years. BMJ 1992; 305: 609-13.

[59] Moline JM, Golden AL, Bar-Chama N, et al. Exposure to hazardous substances and male reproductive health: a research framework. Environ Health Perspect 2000; 108: 803-13.

[60] Rivlin J, Mendel J, Rubinstein S, Etkovitz N, Breitbart H. Role of hydrogen peroxide in sperm capacitation and acrosome reaction. Biol Reprod 2004; 70: 518-22.

[61] Ichimura T, Kawamura M, Mitani A. Co-localized expression of FasL, Fas, Caspase-3 and apoptotic DNA fragmentation in mouse testis after oral exposure to di(2-ethylhexyl)phthalate. Toxicology 2003; 194: 35-42.

[62] Nair R, Shaha C. Diethylstilbestrol induces rat spermatogenic cell apoptosis in vivo through increased expression of spermatogenic cell Fas/FasL system. J Biol Chem 2003; 278: 6470-81.

[63] Qian J, Bian Q, Cui L, Chen J, Song L, Wang X. Octylphenol induces apoptosis in cultured rat Sertoli cells. Toxicol Lett 2006; 166: 178-86.

[64] Ying GG, Williams B, Kookana R. Environmental fate of alkylphenols and alkylphenol ethoxylates-a review. Environ Int 2002; 28: 215-26.

[65] Blake CA, Ashiru OA. Disruption of rat estrous cyclicity by the environmental estrogen 4-tert-octylphenol. Proc Soc Exp Biol Med 1997; 216: 446-51.

[66] Bian Q, Qian J, Xu L, Chen J, Song L, Wang X. The toxic effects of 4-tert-octylphenol on the reproductive system of male rats. Food Chem Toxicol 2006; 44: 1355-61.

[67] Blake CA, Boockfor FR. Chronic administration of the environmental pollutant 4-tert-octylphenol to adult male rats interferes with the secretion of luteinizing hormone, folliclestimulating hormone, prolactin, and testosterone. Biol Reprod 1997; 57: 255-66.

[68] Mishra DP, Shaha C. Estrogen-induced spermatogenic cell apoptosis occurs via the mitochondrial pathway: role of superoxide and nitric oxide. J Biol Chem 2005; 280: 6181-96.

[69] Kim SK, Lee HJ, Yang H, Kim HS, Yoon YD. Prepubertal exposure to 4-tert-octylphenol induces apoptosis of testicular germ cells in adult rat. Arch Androl 2004; 50: 427-41.

[70] Zhou XC, Wei P, Hu ZY, Gao F, Zhou RJ, Liu YX. Role of Fas/FasL genes in azoospermia or oligozoospermia induced by testosterone undecanoate in rhesus monkey. Acta Pharmacol Sin 2001; 22: 1028-33.

[71] Gong Y, Han XD. Nonylphenol-induced oxidative stress and cytotoxicity in testicular Sertoli cells. Reprod Toxicol 2006; 22: 623-30.

[72] Han X, Tu Z, Wang X, Shen S, Hou Y. Nonylphenol induced apoptosis in rat testis through the Fas/FasL pathway. Bull Environ Contam Toxicol 2004; 73: 620-7.

[73] Hahn ME. The aryl hydrocarbon receptor: a comparative perspective. Comp Biochem Physiol C Pharmacol Toxicol Endocrinol 1998; 121: 23-53.

[74] Coutts SM, Fulton N, Anderson RA. Environmental toxicantinduced germ cell apoptosis in the human fetal testis. Hum Reprod 2007; 22: 2912-8. 
[75] vom Saal FS, Hughes C. An extensive new literature concerning low-dose effects of bisphenol A shows the need for a new risk assessment. Environ Health Perspect 2005; 113: 926-33.

[76] Li YJ, Song TB, Cai YY, et al. Bisphenol A exposure induces apoptosis and upregulation of Fas/FasL and caspase-3 expression in the testes of mice. Toxicol Sci 2009; 108: 427-36.

[77] Fiorini C, Tilloy-Ellul A, Chevalier S, Charuel C, Pointis G. Sertoli cell junctional proteins as early targets for different classes of reproductive toxicants. Reprod Toxicol 2004; 18: 413-21.

[78] Takahashi O, Oishi S. Testicular toxicity of dietarily or parenterally administered bisphenol $\mathrm{A}$ in rats and mice. Food Chem Toxicol 2003; 41: 1035-44.

[79] Dalsenter PR, Faqi AS, Webb J, Merker HJ, Chahoud I. Reproductive toxicity and toxicokinetics of lindane in the male offspring of rats exposed during lactation. Hum Exp Toxicol 1997; 16: 146-53.

[80] Saradha B, Vaithinathan S, Mathur PP. Single exposure to low dose of lindane causes transient decrease in testicular steroidogenesis in adult male Wistar rats. Toxicology 2008; 244 : 190-7.

[81] Kuiper GG, Lemmen JG, Carlsson B, et al. Interaction of estrogenic chemicals and phytoestrogens with estrogen receptor beta. Endocrinology 1998; 139: 4252-63.

[82] Gaido KW, Leonard LS, Maness SC, et al. Differential interaction of the methoxychlor metabolite 2,2-bis-(p-hydroxyphenyl)-1,1,1trichloroethane with estrogen receptors alpha and beta. Endocrinology 1999; 140: 5746-53.

[83] Anway MD, Cupp AS, Uzumcu M, Skinner MK. Epigenetic transgenerational actions of endocrine disruptors and male fertility. Science 2005; 308: 1466-9.

[84] Cupp AS, Uzumcu M, Suzuki H, Dirks K, Phillips B, Skinner MK. Effect of transient embryonic in vivo exposure to the endocrine disruptor methoxychlor on embryonic and postnatal testis development. J Androl 2003; 24: 736-45.

[85] Latchoumycandane C, Chitra KC, Mathur PP. The effect of methoxychlor on the epididymal antioxidant system of adult rats. Reprod Toxicol 2002; 16: 161-72.

[86] Latchoumycandane C, Mathur PP. Effect of methoxychlor on the antioxidant system in mitochondrial and microsome-rich fractions of rat testis. Toxicology 2002; 176: 67-75.

[87] Vaithinathan S, Saradha B, Mathur PP. Transient inhibitory effect of methoxychlor on testicular steroidogenesis in rat: an in vivo study. Arch Toxicol 2008; 82: 833-9.

[88] Vaithinathan S, Saradha B, Mathur PP. Methoxychlor-induced alteration in the levels of HSP70 and clusterin is accompanied with oxidative stress in adult rat testis. J Biochem Mol Toxicol 2009; 23: 29-35.

[89] Vaithinathan S, Saradha B, Mathur PP. Methoxychlor induces apoptosis via mitochondria- and FasL-mediated pathways in adult rat testis. Chem Biol Interact 2010; 185: 110-8.
[90] Nakai N, Murata M, Nagahama M, et al. Oxidative DNA damage induced by toluene is involved in its male reproductive toxicity. Free Radic Res 2003; 37: 69-76.

[91] El-Nabi Kamel MA, Shehata M. Effect of toluene exposure on the antioxidant status and apoptotic pathway in organs of the rat. Br J Biomed Sci 2008; 65: 75-9.

[92] Ishigami A, Tokunaga I, Kubo S, Gotohda T. Immunohistochemical study of rat spermatogenesis after toluene-inhalation. Leg Med 2005; 7: 42-6.

[93] Yilmaz B, Canpolat S, Sandal S, et al. Paint thinner exposure inhibits testosterone synthesis and secretion in a reversible manner in the rat. Reprod Toxicol 2006; 22: 791-6.

[94] Kalia S, Bansal MP. p53 is involved in inducing testicular apoptosis in mice by the altered redox status following tertiary butyl hydroperoxide treatment. Chem Biol Interact 2008; 174: 193200.

[95] Kaur P, Kaur G, Bansal MP. Tertiary-butyl hydroperoxide induced oxidative stress and male reproductive activity in mice: role of transcription factor NF-kappaB and testicular antioxidant enzymes. Reprod Toxicol 2006; 22: 479-84.

[96] Kang KH, Kim WH, Choi KH. p21 promotes ceramide-induced apoptosis and antagonizes the antideath effect of Bcl-2 in human hepatocarcinoma cells. Exp Cell Res 1999; 253: 403-12

[97] Kasahara E, Sato EF, Miyoshi M, et al. Role of oxidative stress in germ cell apoptosis induced by di(2-ethylhexyl)phthalate. Biochem J 2002; 365: 849-56.

[98] Boekelheide K, Kleymenova E, Liu K, Swanson C, Gaido KW. Dose-dependent effects on cell proliferation, seminiferous tubules, and male germ cells in the fetal rat testis following exposure to di(n-butyl) phthalate. Microsc Res Tech 2009; 72: 629-38.

[99] Yao PL, Lin YC, Richburg JH. TNF alpha-mediated disruption of spermatogenesis in response to Sertoli cell injury in rodents is partially regulated by MMP2. Biol Reprod 2009; 80: 581-9.

[100] Mishra DP, Pal R, Shaha C. Changes in cytosolic $\mathrm{Ca}^{2+}$ levels regulate $\mathrm{Bcl}-\mathrm{xS}$ and $\mathrm{Bcl}-\mathrm{xL}$ expression in spermatogenic cells during apoptotic death. J Biol Chem 2006; 281: 2133-43.

[101] Lee YS, Yoon HJ, Oh JH, et al. 1,3-Dinitrobenzene induces apoptosis in TM4 mouse Sertoli cells: Involvement of the c-Jun Nterminal kinase (JNK) MAPK pathway. Toxicol Lett 2009; 189: $145-51$

[102] Richburg JH , Nanez A. Fas- or FasL-deficient mice display an increased sensitivity to nitrobenzene-induced testicular germ cell apoptosis. Toxicol Lett 2003; 139: 1-10.

[103] Allenby G, Sharpe RM, Foster PM. Changes in Sertoli cell function in vitro induced by nitrobenzene. Fundam Appl Toxicol 1990; 14 364-75.

[104] Hu JH, Jiang J, Ma YH, et al. Enhancement of germ cell apoptosis induced by ethanol in transgenic mice overexpressing Fas Ligand. Cell Res 2003; 13: 361-7.

[105] Koh PO. Ethanol exposure suppresses survival kinases activation in adult rat testes. J Vet Med Sci 2007; 69: 21-4.

(C) Mathur et al.; Licensee Bentham Open.

This is an open access article licensed under the terms of the Creative Commons Attribution Non-Commercial License (http://creativecommons.org/licenses/by$\mathrm{nc} / 3.0 /$ ), which permits unrestricted, non-commercial use, distribution and reproduction in any medium, provided the work is properly cited. 